\title{
Multilevel analysis of determinants of polygyny among married men in Ethiopia
}

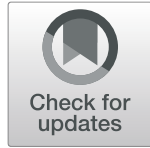

Yitayish Damtie $^{1 *}$ (D) Bereket Kefale ${ }^{1}$, Melaku Yalew ${ }^{1,2}$, Mastewal Arefaynie $^{1}$ and Bezawit Adane ${ }^{2}$

\begin{abstract}
Background: Polygyny occurs when a man has more than one wife at the same time. It often contributes to poor health among family members, particularly young children. It encourages the spread of sexually transmitted infections (STIS) including HIV/AIDS. The determinants of polygyny have not yet been adequately explored in Ethiopia. This study adds to the body of knowledge concerning the prevalence and distribution of polygyny in the country.

Methods: This study is a secondary analysis of the 2016 Ethiopian Demographic and Health Survey (EDHS) data. Using a two-stage stratified cluster sampling, 7470 married men were selected. After verifying the assumptions of multilevel logistic regression analysis, Stata version 14.0 was used to analyse the data. A multilevel mixed-effects logistic regression model was used to identify predictors of polygyny. An adjusted odds ratio with a 95\% confidence interval was used to measure the association. A $p$-value of $<0.05$ was considered to indicate statistical significance.

Results: Age from 30 to 44 years $[A O R=5.78,95 \% \mathrm{Cl}=(3.13,10.7)]$, age from 45 to 59 years $[A O R=16.5,95 \%$ $\mathrm{Cl}=(8.59,31.8)]$, men with primary education or no formal education $[\mathrm{AOR}=3.40,95 \% \mathrm{Cl}=(1.50,7.69)]$, being Muslim $[A O R=2.47,95 \% \mathrm{Cl}=(1.28,4.77)]$, sexual initiation at or above the age of 18 years $[A O R=0.46,95 \%$ $\mathrm{Cl}=(0.30,0.68)]$ and being from a less developed region of Ethiopia $[A O R=3.67,95 \% \mathrm{Cl}=(2.30,5.83)]$ were factors associated with polygyny.
\end{abstract}

Conclusion: Both individual and community level factors were identified as predictors of polygyny. Improving educational attainment and delaying men's sexual debut could encourage the reduction of polygyny in Ethiopia.

Keywords: Polygyny, Polygamy, Married men, Marriage, Ethiopia

\section{Background}

Polygamy is a form of marriage involving multiple spouses. It may occur as polygyny (when a man has multiple wives concurrently, and less commonly, as polyandry (when a woman has multiple husbands concurrently) and as polygynandry (concurrent marriage of two or more wives to two or more husbands) [1-4].

\footnotetext{
* Correspondence: yitutile@gmail.com

'Department of Reproductive and Family Health, School of Public Health, College of Medicine and Health Sciences, Wollo University, PO Box: 1145, Dessie, Ethiopia

Full list of author information is available at the end of the article
}

Polygyny is the commonest form of polygamy. It existed historically in more than $80 \%$ of preindustrial societies [5]. Although the global prevalence of polygyny is small, more than a third of the world's population lives in a community that permits it [6]. The history of polygyny has been practiced for many centuries by various cultures in the world. It has existed as a fundamental part of family law in most African countries. With the arrival of Christianity and colonists, however, it came to be considered as a form of slavery that needed to be eliminated. As a result, its prevalence has been diminishing for decades. Nevertheless, it remains more common in Sub-Saharan Africa (SSA) than anywhere else [7]. The

(C) The Author(s). 2021 Open Access This article is licensed under a Creative Commons Attribution 4.0 International License, which permits use, sharing, adaptation, distribution and reproduction in any medium or format, as long as you give appropriate credit to the original author(s) and the source, provide a link to the Creative Commons licence, and indicate if changes were made. The images or other third party material in this article are included in the article's Creative Commons licence, unless indicated otherwise in a credit line to the material. If material is not included in the article's Creative Commons licence and your intended use is not permitted by statutory regulation or exceeds the permitted use, you will need to obtain permission directly from the copyright holder. To view a copy of this licence, visit http://creativecommons.org/licenses/by/4.0/ The Creative Commons Public Domain Dedication waiver (http://creativecommons.org/publicdomain/zero/1.0/) applies to the data made available in this article, unless otherwise stated in a credit line to the data. 
highest prevalence of polygyny in Africa is found across the so-called 'polygyny belt' stretching from Senegal in West Africa to Tanzania in East Africa [8]. As the Demographic and Health Survey (DHS) data show, 11, 27, and 53\% of marriages in Zimbabwe, Ivory Coast, and Guinea were polygynous respectively [9]. Another DHS reported that polygyny represents $25 \%$ of all marriages in the Democratic Republic of Congo (DRC), $47 \%$ in Sierra Leone, and 53\% in The Gambia [10].

In Ethiopia, although polygyny has declined in recent decades, the national average of polygyny among currently married men was $11 \%$ in 2016 and ranged from $1 \%$ in the Amhara region to $29 \%$ in the Somali region $[11,12]$.

There are several possible reasons for the persistence of polygyny in Ethiopia. Demographic factors such as high infant and child mortality, high male mortality and out-migration, and potentially lethal activities performed by men such as hunting and military combat resulting in a surplus of women and shortage of men, all of which can encourage polygyny $[13,14]$. Religions, mainly Mormonism and Islam, have increased the prevalence of polygyny. Polygyny among Mormons is encouraged whereas, in Islam, it is merely permitted $[13,15]$. The prevalence of polygyny is also affected by age, place of residence, and household wealth [16, 17]. Culture and tradition are the other main factors contributing to the acceptance of polygyny. Polygyny in many African cultures is considered to be a solution for women's infertility and menopause. It also allows men to satisfy sexual needs while their wives are pregnant since sexual relations during pregnancy are taboo in some cultures. Some believe that it is important for a man to continue his family name in future generations. In agricultural societies, polygyny leads to more children who can work in housework, farming, and cattle herding $[4,7,18,19]$.

Polygyny is legally prohibited in Ethiopia by the revised family code proclamation since it undermines women's self-worth, violates gender equality and women's rights, both of which are protected under the Convention on the Elimination of All Forms of Discrimination Against Women (CEDAW) and the Universal Declaration of Human Rights (UDHR) [20]. These legal restrictions on polygyny, however, are rarely enforced.

In addition, polygyny increases the spread of HIV/ AIDS and other Sexually Transmitted Diseases (STDs) [21-23]. Men in a polygynous marriage were 2.6 times more likely to be HIV positive than monogamous men [24] and 2.9 times more likely to be infected with Herpes Simplex Virus (HSV)-2 [25]. Moreover, polygyny is associated with a higher incidence of infant and child mortality [26, 27]. Children from polygynous families experience ill health and early childhood death as a result of malnutrition and HIV/AIDS [28-30]. Adolescents in polygynous families are more likely to have lower self-esteem [31] and poor academic outcomes compared to adolescents from monogamous families [2, 32-34]. Polygyny is also a source of emotional distress and depression imposing detrimental effects on the mental health of wives [35-37].

Identifying the determinants of polygyny is important to meet Sustainable Development Goal (SDG) 3 (to end the HIV epidemic and to decrease neonatal mortality below 12 per 1000 live births by 2030), SDG 5 (to achieve gender equality and empower all women and girls by 2030) [38] and Ethiopian Health Sector Transformation Plan (HSTP) IV (to decrease the under-five mortality rate from 64 to 30 per 1000 live births, to reduce adult HIV incidence by $60 \%$ below 2010 incidence, and to achieve zero new HIV infections among children by 2020) [39].

The reasons for polygyny are multifaceted and vary within and across countries. However, the polygyny practice is more prevalent in sub-Saharan African countries than other world sub-regions [40]. The problems associated with polygyny are numerous, especially in a less developed country like Ethiopia where there is poverty and majority of families earn less than $\$ 1$ per day [41]. Polygyny has been implicated in many studies as one of the factors that promote early marriage, domestic violence, harmful traditional practices, and high fertility [42-45]. Despite the public health importance of polygyny, it is often less studied in Ethiopia. This study aimed to determine individual and community-level factors associated with polygyny among married men in Ethiopia.

\section{Methods}

\section{Study setting}

This study was conducted in Ethiopia, a country with more than 80 ethnic groups [46]. According to the census conducted in 2007, the largest ethnic groups in Ethiopia are Oromo, Amhara, Somali, and Tigray which constituted 43.4, 26.9, 6.2, and $6.1 \%$ of the country's total population respectively [47]. Each ethnic group has a distinct culture, set of customs, traditions, and languages specific to their ethnicity. There are 87 native languages spoken in Ethiopia. They can be classified into Semitic, Cushitic, Omotic, and Nilotic groups. Of these, Amharic is the most common working language while English is the second language of the federal government $[46,48]$. The country also has a long-standing connection with Christianity (Catholic, Orthodox, and Protestant), Islam, and less commonly with Judaism and Paganism [48]. The country's two largest religious faiths are Orthodox Christianity (43.5\%) and Islam (33.9\%) [47]. 


\section{Data source and study population}

This study is a secondary analysis of data from the most recent (2016) EDHS conducted by the central statistical agency with the collaboration of Ethiopian Public Health Institute, Federal Ministry of Health, and the Inner City Fund International which provides technical assistance through its MEASURE DHS project; a USAID-funded program supporting the implementation of population and health surveys in countries worldwide. All of the 7470 married men interviewed in the 2016 EDHS were included in the study.

\section{Conceptual framework and variable measurement}

The dependent variable (polygyny) was dichotomized as "Yes/No." A marriage is said to be polygynous if a man has more than one wife at the time of the interview [49]. The independent variables were both individual and community-level factors. Individual-level factors include socio-demographic factors, household factors and behavioural and health-related factors. Community-level factors were region, place of residence, community-level wealth status and community-level educational status (Fig. 1).

Regions were categorized as less developed (Afar, Somali, Benishangul Gumuz, and Gambela) or more developed (Addis Ababa, Dire Dawa, Amhara, Tigray, Oromia, Southern Nation Nationalities and Peoples (SSNP) region and Harari) [53]. In addition, a total of two community-level factors were generated by aggregating men's characteristics in every 645 clusters. In the 2016 EDHS, a two-stage stratified sampling technique was used for sample selection during the data collection exercise. In the first, a total of 21 sampling strata's were created from each regions after stratifying them into urban and rural areas. Then a total of 645 (202 in urban areas and 443 in rural areas) nonoverlapping smaller geographical units (tagged as clusters) were selected. In the second stage, 28 households per cluster were selected and included in the survey.

Community-level wealth status was generated by dividing the percentage of men with a wealth score of less than $33.3 \%$ (poor wealth index) to the total wealth index in every 645 clusters. As the Shapiro-Wilk normality test (Table 1) and the histogram (Fig. 2) showed, the community-level wealth status was not normally distributed $(p=0.00000)$ and the median value was used as a cut-off point to categorize community wealth status.

Similarly, community-level educational status was computed by using the percentage of men with the two lowest levels of educational attainment (no education and primary education) in each 645 non-overlapping smaller geographical units tagged as clusters. The distribution of community-level educational status was checked by using the Shapiro-Wilk normality test (Table 2) and the histogram (Fig. 3). Since the data was not normally distributed $(P=0.00000)$, the median value was used to categorize community-level educational status.

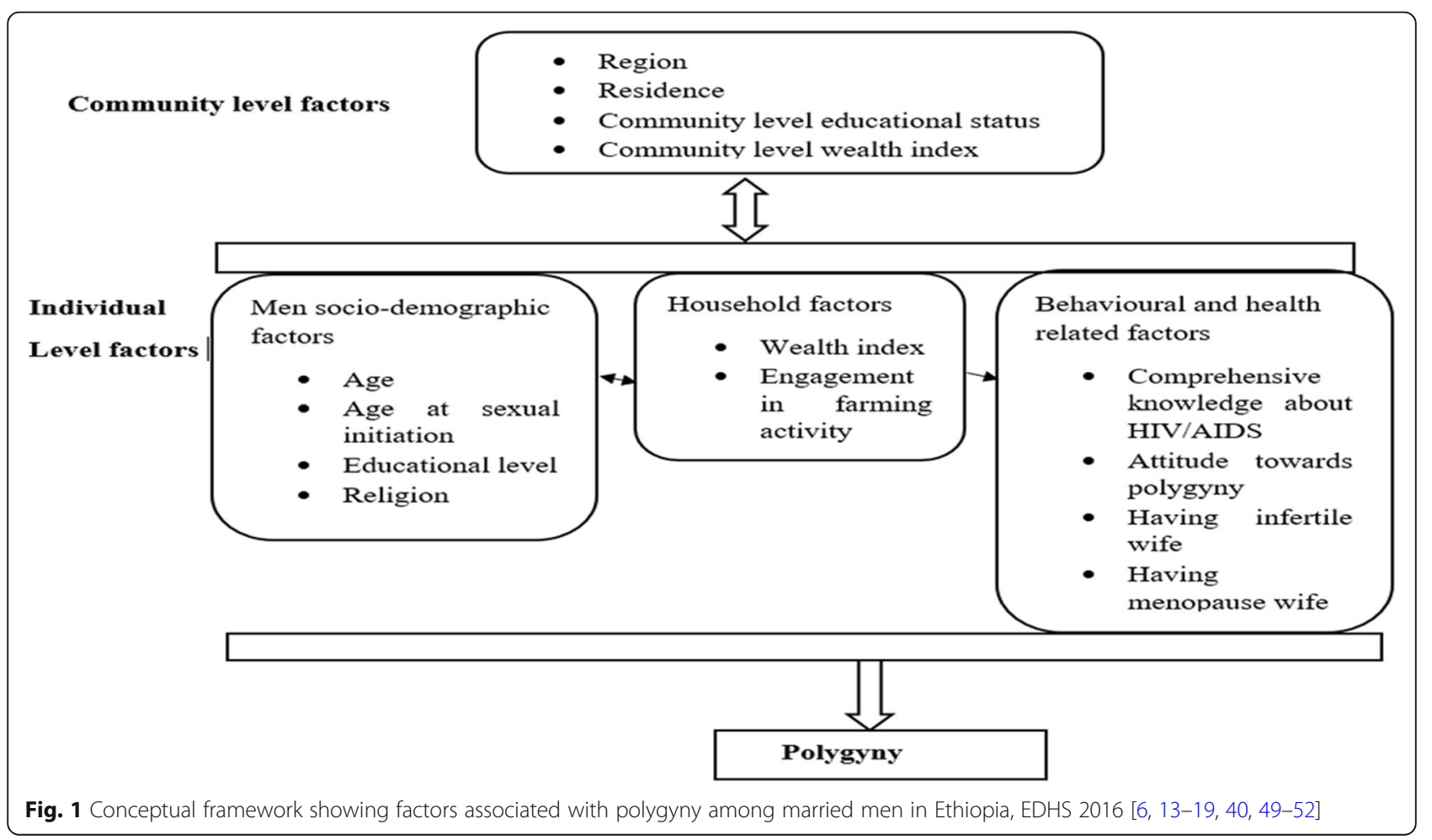


Table 1 Shapiro-Wilk test to check the normality of the distribution of community-level wealth status in Ethiopia, EDHS 2016

\begin{tabular}{llcccc}
\hline Variable & Observations $(\mathbf{N})$ & Shapiro-Wilk test statistics $(\mathbf{W})$ & index for departure $(\mathbf{V})$ & $\mathbf{z}$ - score & Prob $>\mathbf{z}(\boldsymbol{p}$-value $)$ \\
\hline Community level wealth status & 645 & 0.95648 & 18.376 & 7.076 & 0.00000 \\
\hline
\end{tabular}

\section{Data processing and analysis}

The data were cleaned, re-categorized, and analysed by Stata/SE version 14.0. Descriptive statistics such as frequencies, percentages, and medians were computed and the results were presented in tables and texts. Sample weight was used for the compensation of non-responses and unequal selection of samples between each stratum. The Intra-class Correlation Coefficient (ICC) for this study was $38.1 \%$. Due to this and hierarchical nature of EDHS data, a multi-level mixed-effects logistic regression model was used to determine individual and community level factors associated with polygyny. Multilevel mixed-effect analysis is an analytical strategy allowing the simultaneous examination of individual-level and group-level factors. It recognizes group effects and hierarchical structures leading to correct conclusion. On the other hand, individual-level analysis treat independent observations as the units of analysis. It fails to recognize the group effect leading to underestimation of the standard errors of the regression coefficients and overstatement of statistical significance.

The log of the likelihood of being in a polygynous marriage can be modelled as follows [54];

$$
\log \left[\frac{\pi i j}{1-\pi i j}\right]=\beta_{0}+\beta_{1} X_{i j}+B_{2} Z_{i j}+\ddot{\mathrm{E}}_{j}+\mathrm{e}_{\mathrm{ij}}
$$

Where,
- $\mathrm{i}$ is the individual unit and $\mathrm{j}$ is the community units.

- $\pi i j$ is the likelihood of being in a polygynous marriage for the $i^{\text {th }}$ man in the $j^{\text {th }}$ community.

- 1 - rij is the odds of being in a monogamous marriage.

- $\mathrm{X}$ and $\mathrm{Z}$ represent individual and group-level factors respectively.

- The intercept ( $\beta 0)$ represents the effect on the likelihood of being in a polygynous marriage in the absence of the effect of predictor variables.

- $\beta$ 's are the fixed coefficients.

- $\mu \mathrm{j}$ shows the effect of community level factors on polygyny for the $\mathrm{j}^{\text {th }}$ community i.e. the random effect.

- eij indicates the random errors occurred at the individual levels.

Both bi-variable and multivariable multilevel logistic regression analyses were estimated and a $p$-value of $<$ 0.25 was used to screen eligible variables for multivariable multilevel logistic regression analysis. Four models were fitted: Model 0 also known as an empty model (without any predictor variable); Model 1 (include only individual-level predictors); Model 2 (include only group-level predictors) and Model 3 (include both individual and group-level factors). AOR with a 95\% CI was used to measure the association between polygyny and various predictor variables (fixed-effects). The presence of statistical

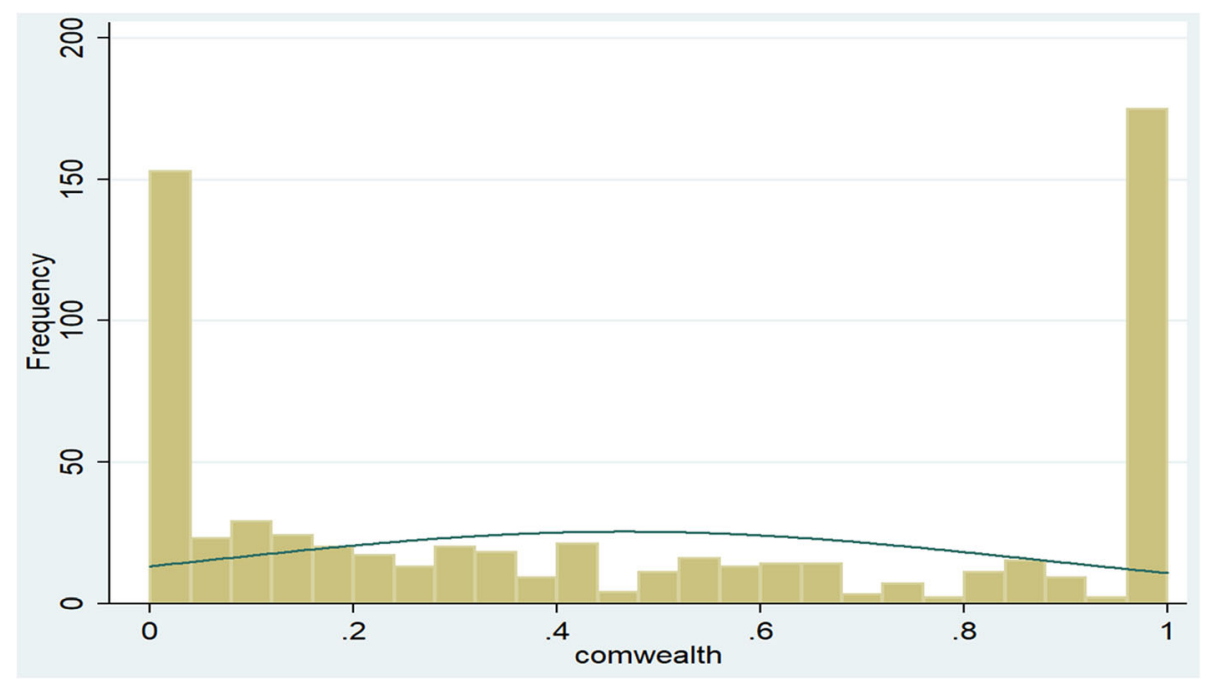

Fig. 2 The histogram used to check the normality of the distribution of community-level wealth status in Ethiopia, EDHS 2016 
Table 2 Shapiro-Wilk test to check the normality of the distribution of community-level educational status in Ethiopia, EDHS 2016

\begin{tabular}{llcccc}
\hline Variable & Observations (N) & Shapiro-Wilk test statistics (W) & index for departure (V) & $\mathbf{z}$ - score & Prob >z ( $\boldsymbol{p}$-value) \\
\hline Community-level educational status & 645 & 0.92592 & 31.280 & 8.369 & 0.00000 \\
\hline
\end{tabular}

significant association was declared at a $p$-value < 0.05 .

The variation between each cluster was reported using Proportional Change in Variance (PCV), ICC and Median Odds Ratio (MOR). The ICC was used to show the degree in which the observation within one cluster resembled each other. It was calculated by using the following formula: $\left[\mathrm{ICC}=\frac{\delta^{2}}{\delta^{2+\frac{\pi^{2}}{3}}}\right.$, where $\delta^{2}$ is the cluster variance.

MOR is the odds ratio between the area at the lowest risk and at the highest risk when two areas are peaked arbitrarily. It was calculated as follows: $[\mathrm{MOR}=\exp$. ( $\left.\left.\sqrt{2 x \delta^{2}+0.6745}\right) \approx \exp (0.95 \delta)\right]$. PCV indicates the total disparity attributed by individual and area-level factors in the multilevel mixed effect model. Log-likelihood test and standard error at the cut-off point of ${ }_{ \pm} 2$ were used to check model fitness and multicollinearity respectively.

\section{Results}

\section{Characteristics of the respondents}

Among the 7470 married men included in the analysis, 3811 (51\%) were 30-44 years old, 1254 (16.8\%) completed secondary and post-secondary education, 3182 (42.6\%) men were Orthodox Tewahido, and 2873 (38.5\%) men were poor (having a wealth score of less than 33\%). Among study participants, 1393 (18.6\%) had their first sexual encounter before age 18 years, 1189 (15.9\%) married men resided in rural areas and 7115
(95.2\%) men were from more developed regions. Among all respondents, 4801(64.3\%) men had no comprehensive knowledge of HIV/AIDS and 3788 (50.7\%) were from communities with a high proportion of poor men (Table 3).

\section{Individual and community-level factors associated with polygyny}

In the final model (model 3) age, educational status, religion, and age at sexual initiation from individual-level factors and region from community-level factors had a statistically significant association with polygyny. Study participants aged from 30 to 44 years were 5.78 times more likely to practice polygyny compared to married men aged $15-29$ years $[\mathrm{AOR}=5.78,95 \% \mathrm{CI}=(3.13$, 10.7)]. Similarly, married men aged $45-59$ years were 16.5 times more likely to practice polygyny compared to married men aged $15-29$ years $[\mathrm{AOR}=16.5,95 \% \mathrm{CI}=$ $(8.59,31.8)]$.

Uneducated men and men with only primary level education were 3.4 more likely to practice polygyny than married men who completed secondary and postsecondary education $[\mathrm{AOR}=3.40,95 \% \mathrm{CI}=(1.50,7.69)]$. Muslim married men were 2.47 times more likely to practice polygyny than Orthodox Tewahido men $[\mathrm{AOR}=$ $2.47,95 \% \mathrm{CI}=(1.28,4.77)]$.

Married men who initiated sex at or above the age of 18 years were $54 \%$ less likely to practice polygyny compared to married men who initiated sex under the age of

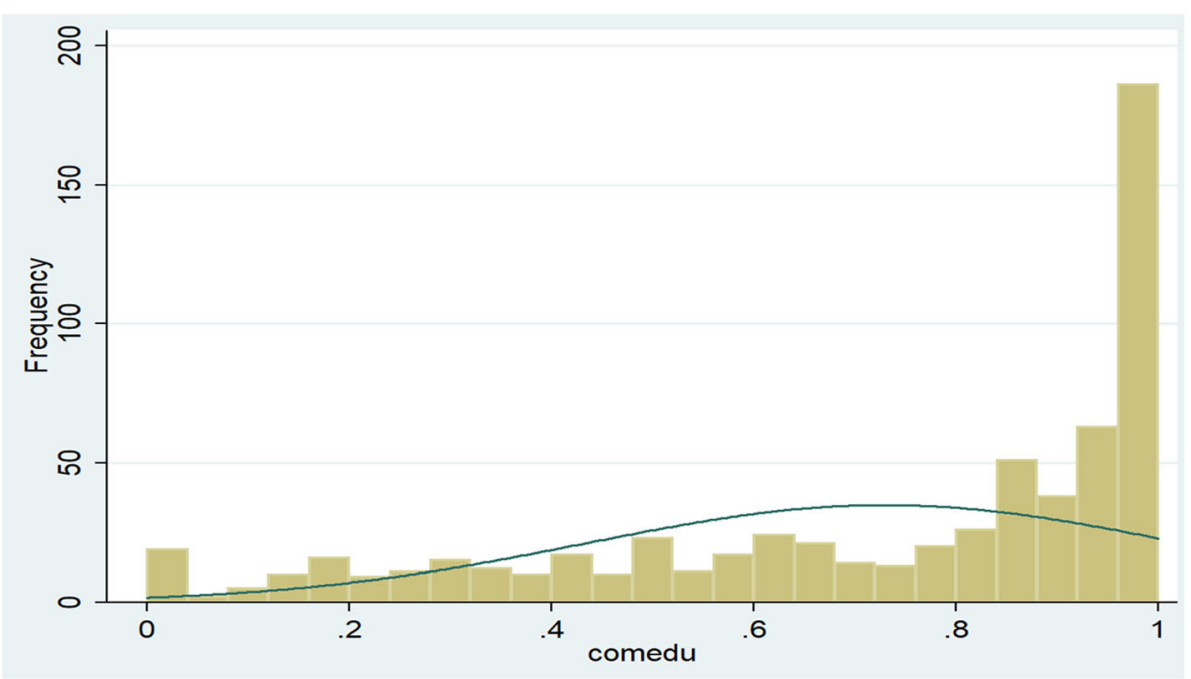

Fig. 3 The histogram used to check the normality of the distribution of community-level educational status in Ethiopia, EDHS 2016 
Table 3 Individual and community-level characteristics of married men in Ethiopia, EDHS 2016 ( $n=7470)$

\begin{tabular}{|c|c|c|c|}
\hline Variable & Category & Number of respondents & Percentage (\%) \\
\hline \multirow[t]{3}{*}{ Age } & $15-29$ years & 1727 & 23.1 \\
\hline & $30-44$ years & 3811 & 51.0 \\
\hline & $45-59$ years & 1932 & 25.9 \\
\hline \multirow[t]{2}{*}{ Education } & Primary and below & 6216 & 83.2 \\
\hline & Secondary and above & 1254 & 16.8 \\
\hline \multirow[t]{3}{*}{ Wealth index } & Poor & 2873 & 38.5 \\
\hline & Middle & 1501. & 20.1 \\
\hline & Rich & 3096 & 41.4 \\
\hline \multirow[t]{4}{*}{ Religion } & Orthodox Tewahido & 3182 & 42.6 \\
\hline & Muslim & 2522 & 33.8 \\
\hline & Protestant & 1612 & 21.6 \\
\hline & Others $^{a}$ & 154 & 2 \\
\hline \multirow[t]{2}{*}{ Age at sexual initiation } & $<18$ years & 1393 & 18.6 \\
\hline & $\geq 18$ years & 6077 & 81.4 \\
\hline \multirow[t]{2}{*}{ Comprehensive HIV knowledge } & Knowledgeable & 4801 & 64.3 \\
\hline & Not knowledgeable & 2669 & 35.7 \\
\hline \multirow[t]{2}{*}{ Residence } & Urban & 1189 & 15.9 \\
\hline & Rural & 6281 & 84.1 \\
\hline \multirow[t]{2}{*}{ Region } & More developed & 7115 & 95.2 \\
\hline & Less developed & 355 & 4.8 \\
\hline \multirow[t]{2}{*}{ Community educational status } & Low & 3120 & 41.8 \\
\hline & High & 4350 & 58.2 \\
\hline \multirow[t]{2}{*}{ Community wealth status } & Low & 3682 & 49.3 \\
\hline & High & 3788 & 50.7 \\
\hline
\end{tabular}

${ }^{a}$ Catholic and traditional religion follower

18 years $[\mathrm{AOR}=0.46,95 \% \mathrm{CI}=(0.30,0.68)]$. Men in less developed regions of Ethiopia were 3.67 more likely to practice polygyny compared to men in more developed regions $[\mathrm{AOR}=3.67,95 \% \mathrm{CI}=(2.30,5.83)]$ (Table 4$)$.

\section{Random effects (measures of variation)}

The practice of polygyny significantly varies across 645 non-overlapping smaller units tagged as clusters. ICC indicated, $38.1 \%$ of the variation in practicing polygyny was attributed to community-level factors. PCV in the final model showed $10.3 \%$ of the variation in polygyny across communities was explained. Likewise, MOR for polygyny in the null model was 3.87 which shows the presence of variation across each cluster (Table 5).

\section{Discussion}

Men between the ages of 30 and 59 years were more likely to be in a polygynous marriage than younger age men. The reason could be men aged 30 and older are more likely to be non-educated and lead their lives based on cultural traditions. In addition, men over 30 years are more likely to be economically stable and so able to afford multiple wives $[55,56]$.

Being Muslim was positively associated with polygyny in Ethiopia. That was also found in a study in SSA and Ghana [40,49] and in a cross-national analysis of 26 African countries [57]. The reason could be polygyny's encouragement by Islam. Islamic doctrine permits a man to have up to four wives for creating and sustaining the Muslim family and to populate the world with believers [58].

Being uneducated or educated only at the primary level was positively associated with polygyny. That was also found in a study conducted in the city of Bastak, Iran [51]. Polygyny is a marriage of a man with several women which is a common practice in Africa including Ethiopia. The practice is more prevalent among poorly educated men or those with no formal education than their highly educated counterparts. Education provides information that can change the orientation of men towards this social practice and previous studies have established that good education influences small family size. Many men in Africa are in polygyny marriage today 
Table 4 Multilevel logistic regression analysis of individual and community-level factors associated with polygyny among married men in Ethiopia, EDHS $2016(n=7470)$

\begin{tabular}{|c|c|c|c|c|c|}
\hline Individual and community-level factors & $\begin{array}{l}\text { COR } \\
(95 \% \mathrm{Cl})\end{array}$ & $\begin{array}{l}\text { Model } 0 \\
\text { ICC }=38.1 \%\end{array}$ & $\begin{array}{l}\text { Model } 1 \\
\text { AOR }(95 \% \mathrm{Cl})\end{array}$ & Model 2 AOR(95\% Cl) & $\begin{array}{l}\text { Model } 3 \\
\text { AOR }(95 \% \mathrm{Cl})\end{array}$ \\
\hline \multicolumn{6}{|l|}{ Age } \\
\hline $15-29$ years & 1 & & 1 & & 1 \\
\hline $30-44$ years & $5.60(3.10,10.1)$ & & $5.73(3.1,10.6)$ & & $5.78(3.13,10.7)$ \\
\hline $45-59$ years & $16.0(8.69,29.6)$ & & $16.1(8.37,30.9)$ & & $16.5(8.59,31.8)$ \\
\hline \multicolumn{6}{|l|}{ Education } \\
\hline Primary and below & $5.26(2.61,10.6)$ & & $3.87(1.83,8.20)$ & & $3.40(1.50,7.69)$ \\
\hline Secondary and above & 1 & & 1 & & 1 \\
\hline \multicolumn{6}{|l|}{ Religion } \\
\hline Orthodox & 1 & & 1 & & 1 \\
\hline Muslim & $3.33(1.92,5.79)$ & & $3.57(1.93,6.62)$ & & $2.47(1.28,4.77)$ \\
\hline Protestant & $1.98(0.96,4.07)$ & & $2.23(1.03,4.82)$ & & $1.97(0.90,4.30)$ \\
\hline Other ${ }^{a}$ & $2.98(0.76,11.7)$ & & $3.48(0.88,13.7)$ & & $2.98(0.77,11.6)$ \\
\hline \multicolumn{6}{|l|}{ Age at sexual initiation } \\
\hline under 18 years & 1 & & 1 & & 1 \\
\hline At or above 18 years & $0.54(0.38,0.77)$ & & $0.45(0.30,0.67)$ & & $0.46(0.30,0.68)$ \\
\hline \multicolumn{6}{|l|}{ Comprehensive knowledge of HIV/AIDS } \\
\hline Knowledgeable & $1.31(0.89,1.93)$ & & $1.20(0.82,1.76)$ & & $1.12(0.76,1.66)$ \\
\hline Not knowledgeable & 1 & & 1 & & 1 \\
\hline \multicolumn{6}{|l|}{ Residence } \\
\hline Urban & 1 & & & 1 & 1 \\
\hline Rural & $4.96(2.51,9.79)$ & & & $4.42(2.10,9.28)$ & $3.00(0.32,6.82)$ \\
\hline \multicolumn{6}{|l|}{ Region } \\
\hline More developed & 1 & & & 1 & 1 \\
\hline Less developed & $4.63(3.26,6.58)$ & & & $4.36(2.99,6.35)$ & $3.67(2.30,5.83)$ \\
\hline \multicolumn{6}{|l|}{ Community-level educational status } \\
\hline Low & 1 & & & 1 & 1 \\
\hline High & $1.51(1.00,2.28)$ & & & $0.92(0.60,1.41)$ & $0.79(0.49,1.26)$ \\
\hline \multicolumn{6}{|l|}{ Community-level wealth status } \\
\hline Low & 1 & & & 1 & 1 \\
\hline High & $0.43(0.29,0.65)$ & & & $0.87(0.54,1.39)$ & $0.94(0.57,1.53)$ \\
\hline
\end{tabular}

Model 0 (null model) - without independent predictors, Model 1- only individual-level factors, Model 2- only community-level factors; Model 3- both individual and community-level factors; ${ }^{\text {a }}$ Catholic and traditional religion follower; COR crude odds ratio, AOR adjusted odds ratio

Table 5 Measure of variation for polygyny at cluster level in multilevel logistic regression analysis, EDHS 2016

\begin{tabular}{lllll}
\hline Measure of variation & $\begin{array}{l}\text { Model } \mathbf{0} \\
\mathbf{9 5 \%} \mathbf{C l})\end{array}$ & $\begin{array}{l}\text { Model } \mathbf{1} \\
\mathbf{( 9 5 \%} \mathbf{C l})\end{array}$ & Model 2 (95\%Cl) & Model 3 $\mathbf{( 9 5 \% \mathbf { C l } )}$ \\
\hline Variance & $2.03(1.56,2.62)$ & $1.93(1.40,2.67)$ & $1.84(1.40,2.40)$ & $1.82(1.39,2.71)$ \\
ICC (\%) & 38.1 & 36.9 & 35.9 & 35.6 \\
PCV (\%) & Reference & 4.9 & 9.4 & 10.3 \\
MOR & 3.87 & 3.74 & 3.63 & 3.60 \\
Model fitness & & & & -1331.4 \\
\multicolumn{1}{l}{ Log-likelihood } & -1512.2 & -1347.5 & -1481.2 & \\
\hline
\end{tabular}

Model 0 (null model)- without independent predictors, Model 1- only individual-level factors, Model 2- only community-level factors, Model 3- both individual and community-level factors, ICC-Intra-class correlation coefficient, PCV- Proportional change in variance, and MOR- Median odds ratio 
because of their interest in large family size which in some cases is a cultural demand in traditional African settings [40].

Initiating sex before age 18 is positively associated with polygyny. That was also found in a study in Uganda [52]. The possible justification could be, individuals who initiated sex before age 18 are more likely to adapt and maintain the behavior for a long time and will have multiple, casual, and concurrent sexual partnerships at a later age [59].

Living in less developed regions within Ethiopia also has a positive association with polygyny similar to a study conducted in Ghana, Senegal, Kenya, and Zimbabwe [40]. The possible reason is that most men in less developed regions are agrarian as a result, they tend to marry more than one wife and produce several children to ensure division of labor and enhance productivity. Moreover, people in less developed regions are dogma-bound and affected by the deep-rooted traditional beliefs and values which makes them less penetrated by modernization. On the other hand, people in urban settings are highly affected by western lifestyle and have a chance to media exposure so that traditional polygamy is no longer the norm and are likely to practice monogamous marriage $[7,19,50]$.

\section{Summary}

Even though polygynous marriage is formally prohibited by the revised family code proclamation [20], it is quite common in Ethiopia where $11 \%$ of currently married men practice polygynous marriage [11]. Polygynous marriage adversely affects the health of the child and wives. It also violates gender equality and women's rights which are protected under different conventions. Improving maternal and child health, achieving gender equality, and ending HIV/AIDS epidemic are the primary intervention areas of the government that have to be achieved by 2030 [38]. So, the national government should synthesize legal institutions to enforce legal restrictions according to the proclamation. In addition, efforts should be made to delay sexual debut and to increase the education service coverage among men in all regions of the nation.

This study has strengths and limitations. By considering the variation among 643 non-overlapping smaller geographical units (clusters) a multilevel mixed-effects logistic regression model was used to identify individual and community-level factors. Furthermore, the findings of this research can be generalized to the Ethiopian population since the study was done on nationally representative data. A limitation of this study is its lack of data on infertility and menopause of the first wife and occupation, most especially farming. The inability to determine causality is inevitable due to the crosssectional nature of the data.

\section{Conclusions}

Individual-level factors; age, religion, educational status, and age at sexual initiation and the community-level factor region had statistically significant associations with polygyny. So, the preexisting strategies and policies about universal education to all should be the area of emphasis especially for those who are uneducated or educated only at the primary level. Furthermore, extra efforts are still required to change the values and attitudes of the people towards polygyny. Sexuality education should also be given to delay age at sexual initiation and the government should give special attention to less developed regions. Further qualitative research to explore different beliefs, customs, cultures, and traditions associated with polygyny is recommended. Further research using spatial analysis is also recommended to provide area-specific interventions.

\begin{abstract}
Abbreviations
AOR: Adjusted Odds Ratio; Cl: Confidence Interval; CEDAW: Convention on the Elimination of All Forms of Discrimination against Women;

DRC: Democratic Republic Congo; EDHS: Ethiopia Demographic and Health Survey; HSTP: Health Sector Transformation Plan; HSV: Herpes Simplex Virus; HIV/ AIDS: Human Immunodeficiency Virus/ Acquired Immune Deficiency Syndrome; ICC: Intra-cluster Correlation Coefficient; MOR: Median Odds Ratio; PCV: Proportional Change in Variance; STD: Sexual Transmitted Diseases; SNNP: Southern Nation Nationalities and Peoples; SSA: Sub Saharan Africa; SDG: Sustainable Development Goals; UDHR: Universal Declaration of Human Rights
\end{abstract}

\section{Acknowledgments}

The authors would like to acknowledge the DHS program for providing an authorization letter and EDHS dataset to conduct this study.

\section{Authors' contributions}

YD: initiated the research concept, analyze and interpreted the data; BK \& MY: wrote the manuscript; MA \& BA: critically revised the manuscript. All authors read and approved the final manuscript.

Funding

There is no specific funding for this study.

\section{Availability of data and materials}

The datasets used and/or analysed during this study are available from the corresponding author on reasonable request.

\section{Declarations}

Ethics approval and consent to participate

Ethical clearance was obtained from the Ethical Review Committee of Wollo University College of Medicine and Health Science. An authorization letter to download the EDHS data set was also obtained from CSA after requesting the www.measuredhs.com website. The requested data were treated with strict confidentiality and used only for the study purpose. No attempt was made to interact with any individual respondent nor was household data included in the survey. Complete information regarding ethical issues is available in the EDHS report.

Consent for publication

Not applicable. 


\section{Competing interests}

The authors declare that they have no competing interests.

\section{Author details}

'Department of Reproductive and Family Health, School of Public Health, College of Medicine and Health Sciences, Wollo University, PO Box: 1145, Dessie, Ethiopia. ${ }^{2}$ Department of Epidemiology and Biostatistics, School of Public Health, College of Medicine and Health Sciences, Wollo University, Dessie, Ethiopia.

\section{Received: 28 July 2020 Accepted: 31 August 2021} Published online: 15 September 2021

\section{References}

1. Al-Krenawi A, Graham JR. Helping professional practice with indigenous peoples: the Bedouin-Arab case. USA: University Press of America; 2009.

2. Al-Krenawi A, Slonim-Nevo V. Psychosocial and familial functioning of children from polygynous and monogamous families. J Soc Psychol. 2008; 148(6):745-64. https://doi.org/10.3200/SOCP.148.6.745-764.

3. Al-Krenawi A. Women from polygamous and monogamous marriages in an out-patient psychiatric clinic. Transcult Psychiatry. 2001;38(2):187-99. https:// doi.org/10.1177/136346150103800203.

4. Elbedour S, Onwuegbuzie AJ, Caridine C, Abu-Saad H. The effect of polygamous marital structure on behavioral, emotional, and academic adjustment in children: a comprehensive review of the literature. Clin Child Fam Psychol Rev. 2002;5(4):255-71. https://doi.org/10.1023/A:102092512301 6.

5. Hassouneh-Phillips D. Polygamy and wife abuse: a qualitative study of Muslim women in America. Health Care Women Int. 2001;22(8):735-48. https://doi.org/10.1080/073993301753339951.

6. Thobejane TD, Flora T. An exploration of polygamous marriages: A worldview. Mediterr J Soc Sci. 2014;5(27 P2):1058.

7. Mwambene L. What is the future of polygyny (polygamy) in Africa? J Potchefstroomse Elektroniese Regsblad. 2017;20(1):1-33.

8. Jacoby HG. The economics of polygyny in sub-Saharan Africa: female productivity and the demand for wives in Côte d'Ivoire. J Polit Econ. 1995; 103(5):938-71. https://doi.org/10.1086/262009.

9. Bove R, Valeggia C. Polygyny and women's health in sub-Saharan Africa. Soc Sci Med. 2009:68(1):21-9. https://doi.org/10.1016/..socscimed.2008.09.045.

10. Pis L. Understanding women's lives in polygamous marriages; 2017.

11. Ethiopia Demographic and Health Survey. Key indicators report. Addis Ababa, Ethiopia, and Rockville: Ethiopia Demographic and Health Survey; 2016.

12. CSA I. Ethiopia demographic and health survey: key indicators report. Addis Ababa, Ethiopia and Rockville: CSA and ICF; 2000.

13. Fulas D. The legal framework regulating polygamy in Ethiopia: an assessment in light of Liberal feminist legal theory and international human rights law; 2018

14. Gibson MA, Mace R. Polygyny, reproductive success and child health in rural Ethiopia: why marry a married man? J Biosoc Sci. 2007;39(2):287-300. https://doi.org/10.1017/S0021932006001441.

15. Al-Shamsi MSA, Fulcher LC. The impact of polygamy on United Arab Emirates' first wives and their children. Int J Child Fam Welfare. 2005;18(1): 46-55.

16. OKORJE A. African polygamy: church action; community reaction, and personal interaction. Indian J Theol. 1994;36(2):2-9.

17. Strassmann Bl. Polygyny as a risk factor for child mortality among the Dogon. Curr Anthropol. 1997;38(4):688-95. https://doi.org/10.1086/204657.

18. Hussein B. Polygamy: an ethical case study. Mission Focus. 2002;10:81-91.

19. Slonim-nevo V, Al-Krenawi A. Success and failure among polygamous families: the experience of wives, husbands, and children. Fam Process. 2006;45(3):311-30. https://doi.org/10.1111/j.1545-5300.2006.00173.x.

20. Federal Negarit Gazetta of the Federal Democratic Republic of Ethiopia: The Revised Family Code, 2000

21. Eaton JW, Hallett TB, Garnett GP. Concurrent sexual partnerships and primary HIV infection: a critical interaction. AIDS Behav. 2011;15(4):687-92. https://doi.org/10.1007/s10461-010-9787-8.

22. Halperin DT, Epstein H. Concurrent sexual partnerships help to explain Africa's high HIV prevalence: implications for prevention. Lancet. 2004 364(9428):4-6. https://doi.org/10.1016/S0140-6736(04)16606-3.
23. Reniers G, Tfaily R. Polygyny, partnership concurrency, and HIV transmission in sub-Saharan Africa. Demography. 2012;49(3):1075-101. https://doi.org/1 0.1007/s13524-012-0114-z.

24. Reniers G, Tfaily R. Polygyny and HIV in Malawi. Demogr Res. 2008;19(53): 1811-30. https://doi.org/10.4054/DemRes.2008.19.53.

25. Halton K, Ratcliffe AA, Morison L, West B, Shaw M, Bailey R, et al. Herpes simplex 2 risk among women in a polygynous setting in rural West Africa. Aids. 2003;17(1):97-103. https://doi.org/10.1097/00002030-2 00301030-00013.

26. Smith-Greenaway E, Trinitapoli J. Polygynous contexts, family structure, and infant mortality in sub-Saharan Africa. Demography. 2014;51(2):341-66. https://doi.org/10.1007/s13524-013-0262-9.

27. Omariba DWR, Boyle MH. Family structure and child mortality in subSaharan Africa: cross-national effects of polygyny. J Marriage Fam. 2007; 69(2):528-43. https://doi.org/10.1111/j.1741-3737.2007.00381.x

28. Hadley C. Is polygyny a risk factor for poor growth performance among Tanzanian agropastoralists? Am J Phys Anthropol. 2005;126(4):471-80. https://doi.org/10.1002/ajpa.20068.

29. Brahmbhatt H, Bishai D, Wabwire-Mangen F, Kigozi G, Wawer M, Gray RH, et al. Polygyny, maternal HIV status and child survival: Rakai, Uganda. Soc Sci Med. 2002;55(4):585-92. https://doi.org/10.1016/S0277-9536(01)00189-7.

30. Lawson DW, Gibson MA. Polygynous marriage and child health in subSaharan Africa: what is the evidence for harm? Demogr Res. 2018:39:177208. https://doi.org/10.4054/DemRes.2018.39.6.

31. Al-Krenawi A, Graham JR, Slonim-Nevo V. Mental health aspects of ArabIsraeli adolescents from polygamous versus monogamous families. J Soc Psychol. 2002;142(4):446-60. https://doi.org/10.1080/00224540209603911.

32. Al-Krenawi A, Lightman ES. Learning achievement, social adjustment, and family conflict among Bedouin-Arab children from polygamous and monogamous families. J Soc Psychol. 2000;140(3):345-55. https://doi.org/1 0.1080/00224540009600475.

33. Elbedour S, Bart WM, Hektner J. Intelligence and family marital structure: the case of adolescents from monogamous and polygamous families among Bedouin Arabs in Israel. J Soc Psychol. 2003;143(1):95-110. https://doi.org/1 0.1080/00224540309598433.

34. Adenike AO. Effects of family type (monogamy or polygamy) on students' academic achievement in Nigeria. Int J Psychol Counsel. 2013;5(7):153-6.

35. Al-Krenawi A, Graham JR. A comparison of family functioning, life and marital satisfaction, and mental health of women in polygamous and monogamous marriages. Int J Soc Psychiatry. 2006;52(1):5-17. https://doi. org/10.1177/00207640060061245.

36. Ozkan M, Altindag A, Oto R, Sentunali E. Mental health aspects of Turkish women from polygamous versus monogamous families. Int J Soc Psychiatry. 2006;52(3):214-20. https://doi.org/10.1177/0020764006067207.

37. Shepard LD. The impact of polygamy on women's mental health: a systematic review. Epidemiol Psychiatry Sci. 2013;22(1):47-62. https://doi. org/10.1017/S2045796012000121.

38. Assembly G. Sustainable development goals. SDGs Transform Our World. 2015;2030.

39. Federal Ministry of Health: Health Sector Transformation Plan 2015/162019/20 (2008-2012 EFY). Addis Ababa: Federal Democratic Republic of Ethiopia Ministry of Health; 2015

40. Hayase $Y$, Liaw KL. Factors on polygamy in sub-Saharan Africa: findings based on the demographic and health surveys. Dev Econ. 1997;35(3):293327. https://doi.org/10.1111/j.1746-1049.1997.tb00849.x.

41. Haradhan M. Ethiopia: a socio-economic study. J Business Manag Admin. 2013:1(5):59-74

42. Ahinkorah BO. Polygyny and intimate partner violence in sub-Saharan Africa: evidence from 16 cross-sectional demographic and health surveys. SSMPopulation Health. 2021;13:100729. https://doi.org/10.1016/.jssmph.2021.100729.

43. Pebley A, Mbugua W, Goldman N. Polygyny and fertility in sub-Saharan Africa. Fertil Determin Res Notes. 1988;21:6-10.

44. Chojnacka H. Early marriage and polygyny: feature characteristics of nuptiality in Africa. Genus. 2000 Jul;1:179-208.

45. Gaffney-Rhys R. A comparison of child marriage and polygamy from a human rights perspective: are the arguments equally cogent? J Soc Welfare Fam. 2012;34(1):49-61. https://doi.org/10.1080/09649069.2012.675464.

46. Munroy-Hay S. Ethiopia, the unknown land: a cultural and historical guide; 2002.

47. Population and Census Commission: Summary and statistical report of the 2007 population and housing census, 2007. 
48. Adamu AY. Diversity in Ethiopia: A historical overview of political challenges. Int J Commun Divers. 2013;12(1, 3):-27. https://doi.org/10.18848/2327-0004/ CGP/V12i03/39924.

49. Klomegah R. Socio-economic characteristics of Ghanaian women in polygynous marriages. J Comp Fam Stud. 1997;28(1):73-88. https://doi.org/1 0.3138/jcfs.28.1.73.

50. Muthengi JK. Polygamy and the church in Africa: biblical, historical, and practical perspectives. Afr J Evang Theol. 1995;14(2):55-78.

51. Salehi H, Mehrpour H, Raoufi M. Study of cultural-social factors associated with polygamy in the Bastak City, Iran. J Educ Manag Stud. 2013;3:345-8.

52. Maher D, Waswa L, Karabarinde A, Baisley K: Concurrent sexual partnerships and associated factors: a cross-sectional population-based survey in a rural community in Africa with a generalized HIV epidemic. BMC Public Health 2011, 11(1):1-15, DOl: https://doi.org/10.1186/1471-2458-11-651.

53. Gebre-Egziabhere T. Emerging regions in Ethiopia: are they catching up with the rest of Ethiopia? East Afr Soc Sci Res Rev. 2018;34(1):1-36. https:// doi.org/10.1353/eas.2018.0000.

54. Hox JJ, Moerbeek M, Moerbeek M. Schoot Rvd: multilevel analysis: quantitative methodology series; 2018. https://doi.org/10.4324/978131 5650982.

55. Caldwell J, Caldwell P, Ankrah EM, Anarfi JK, Agyeman DK, Awusabo-Asare K, et al. African families and AIDS: context, reactions and potential interventions. Health Transition Rev. 1993;1:1-16.

56. Philipson T, Posner RA. The microeconomics of the AIDS epidemic in Africa. Popul Dev Rev. 1995;21(4):835-48. https://doi.org/10.2307/2137776.

57. Wagner N, Rieger M. Polygyny and child growth: evidence from twenty-six African countries. Fem Econ. 2015;21(2):105-30. https://doi.org/10.1080/1354 5701.2014.927953.

58. Esposito JL. Women in Muslim family law: Syracuse University press; 2001.

59. Kaplan DL, Jones EJ, Olson EC, Yunzal-Butler CB. Early age of first sex and health risk in an urban adolescent population. J Sch Health. 2013;83(5):3506. https://doi.org/10.1111/josh.12038.

\section{Publisher's Note}

Springer Nature remains neutral with regard to jurisdictional claims in published maps and institutional affiliations.

Ready to submit your research? Choose BMC and benefit from:

- fast, convenient online submission

- thorough peer review by experienced researchers in your field

- rapid publication on acceptance

- support for research data, including large and complex data types

- gold Open Access which fosters wider collaboration and increased citations

- maximum visibility for your research: over $100 \mathrm{M}$ website views per year

At $\mathrm{BMC}$, research is always in progress.

Learn more biomedcentral.com/submissions 